\title{
Properties of AlN/GaN Heterostructures Grown at Low Growth Temperatures with Ammonia and Dimethylhydrazine
}

\author{
Caroline E. Reilly ${ }^{1, *(\mathbb{D}, \text { Nirupam Hatui }}{ }^{2}{ }^{(0)}$, Thomas E. Mates ${ }^{1}$, Pratik Koirala ${ }^{3}$, Adedapo A. Oni ${ }^{3}$, \\ Shuji Nakamura ${ }^{1,2}$, Steven P. DenBaars ${ }^{1,2}$ and Stacia Keller ${ }^{2}$ D \\ 1 Materials Department, University of California, Santa Barbara, CA 93106, USA; \\ tmates@mrl.ucsb.edu (T.E.M.); snakamura@ucsb.edu (S.N.); spdenbaars@ucsb.edu (S.P.D.) \\ 2 Electrical and Computer Engineering Department, University of California, Santa Barbara, CA 93106, USA; \\ nirupam@ucsb.edu (N.H.); stacia@ece.ucsb.edu (S.K.) \\ 3 Intel Corporation, Santa Clara, CA 95052, USA; pratik.koirala@intel.com (P.K.); \\ adedapo.a.oni@intel.com (A.A.O.) \\ * Correspondence: cereilly@ucsb.edu
}

check for updates

Citation: Reilly, C.E.; Hatui, N.; Mates, T.E.; Koirala, P.; Oni, A.A.; Nakamura, S.; DenBaars, S.P.; Keller, S. Properties of AlN/GaN Heterostructures Grown at Low Growth Temperatures with Ammonia and Dimethylhydrazine. Crystals 2021, 11, 1412. https://doi.org/ $10.3390 /$ cryst11111412

Academic Editor: Shujun Zhang

Received: 10 November 2021

Accepted: 16 November 2021

Published: 19 November 2021

Publisher's Note: MDPI stays neutral with regard to jurisdictional claims in published maps and institutional affiliations.

Copyright: (c) 2021 by the authors. Licensee MDPI, Basel, Switzerland. This article is an open access article distributed under the terms and conditions of the Creative Commons Attribution (CC BY) license (https:// creativecommons.org/licenses/by/ $4.0 /)$.

\begin{abstract}
The integration of different electronic materials systems together has gained increasing interest in recent years, with the III-nitrides being a favorable choice for a variety of electronic applications. To increase flexibility in integration options, growing nitrides material directly on semi-processed wafers would be advantageous, necessitating low temperature (LT) growth schemes. In this work, the growth of $\mathrm{AlN}$ and $\mathrm{GaN}$ was conducted via metalorganic chemical vapor deposition (MOCVD) using both $\mathrm{NH}_{3}$ and $\mathrm{DMHy}$ as $\mathrm{N}$-precursors. The relationships between growth rate versus temperature were determined within the range of 300 to $550{ }^{\circ} \mathrm{C}$. The growth of $\mathrm{AlN} / \mathrm{GaN}$ heterostructures was also investigated herein, employing flow modulation epitaxy MOCVD at $550{ }^{\circ} \mathrm{C}$. Subsequent samples were studied via atomic force microscopy, X-ray diffraction, TEM, and Hall measurements. Two-dimensional electron gases were found in samples where the LT AlN layer was grown with $\mathrm{NH}_{3}$, with one sample showing high electron mobility and sheet charge of $540 \mathrm{~cm}^{2} / \mathrm{V} \cdot \mathrm{s}$ and $3.76 \times 10^{13} \mathrm{~cm}^{-2}$, respectively. Inserting a LT GaN layer under the LT AlN layer caused the mobility and charge to marginally decrease while still maintaining sufficiently high values. This sets the groundwork towards use of LT nitrides MOCVD in future electronic devices integrating III-nitrides with other materials.
\end{abstract}

Keywords: nitrides; electronics; integrated electronics; MOCVD; epitaxy

\section{Introduction}

Increasing performance and maturity of the III-N material system in electronic applications, such as in high-electron mobility transistors (HEMTs), has made the (Al,Ga)N system an attractive choice for next generation electronics [1-3]. The success of the nitrides has come at a time when integration of different materials, to utilize each of their advantageous properties, is of great interest [4-10]. In general, the integration of various materials systems can be done either through growth-based integration, where one material is grown on or with another, or processing-based integration, where the materials are grown separately and then combined during device processing steps [6]. Both methods have their benefits, with processing-based integration being more readily available currently and with growthbased integration having the potential to widen the device design space considerably. To make growth-based integration of nitrides more accessible, epitaxial growth techniques must be compatible with materials of interest for integration by using temperature and pressure conditions that will not harm the substrate or already existing structures. Taking into consideration growth on semi-processed wafers, the deposition temperature at the wafer surface should be kept at or under about $500{ }^{\circ} \mathrm{C}$. 
While this may be within a manageable temperature range when using molecular beam epitaxy (MBE) as growth technique [11-13], the temperatures for metalorganic chemical vapor deposition (MOCVD) typically exceed $1000^{\circ} \mathrm{C}$ for high quality (Al,Ga)N. As MOCVD is more scalable than MBE and therefore the industry standard for the growth of nitrides, having the capability to use MOCVD to grow $(\mathrm{Al}, \mathrm{Ga}) \mathrm{N}$ at low growth temperatures would be beneficial. Low temperature (LT) growth via MOCVD can lead to poor morphology and high impurity incorporation, necessitating specialized growth techniques to maintain film quality at these very low temperatures. Pulsed growth techniques involving modulating the flow of one or more of the precursors have shown to improve film quality [14-16]. These techniques include migration enhanced epitaxy (MEE), atomic layer epitaxy (ALE), or flow modulation epitaxy (FME) and work by allowing surface adatoms sufficient time to diffuse to steps or kinks on the crystal surface, thereby counteracting the effects of lower adatom motion caused by lower growth temperatures. Using pulsed growth schemes such as FME can be particularly beneficial for Al-containing films, as the diffusion lengths of Al-species are lower compared to Ga- or In-species [17-19]. It has also been shown that pulsed growth schemes can lower impurity incorporation in films [20-23].

Another proposed method towards lowering MOCVD growth temperatures while maintaining film quality has been utilizing alternative precursors which decompose at lower temperatures compared to the standard precursors. Concerns that $\mathrm{NH}_{3}$ has a low cracking efficiency at reduced growth temperatures has made the study of alternative $\mathrm{N}$ precursors desirable. Hydrazine is one of the precursors of interest for these studies, where weaker bonds in hydrazine compared to $\mathrm{NH}_{3}$ result in a lower decomposition temperature. However, the explosive nature of hydrazine and concerns for health and safety make it difficult to work with such that other studies have considered dimethylhydrazine (DMHy) and tertiarybutylhydrazine as possible alternatives [24-28]. Several studies have shown the viability of these precursors, and the use of the arsine counterparts to these metalorganic precursors in MOCVD growth of III-As materials provides additional support for their use [29].

Previously, FME growth of GaN and AlN films via MOCVD at temperatures below $550{ }^{\circ} \mathrm{C}$ on $\mathrm{GaN}$-on-sapphire templates was demonstrated [18,20]. In the AlN study, electrical measurements showed the existence of a two-dimensional electron gas (2DEG) at the AlN/GaN interface; however, the sheet charge densities were lower than expected due to unintentional Ga-incorporation into AIN [18]. Elevated C and O impurity levels in the FME GaN films also led to concerns [20]. In this study we report on the further improvement of the properties of the two-dimensional electron gas (2DEG) forming at the interface of AlN layers grown via $\mathrm{FME}$ at $550{ }^{\circ} \mathrm{C}$ with $\mathrm{NH}_{3}$ and semi-insulating $\mathrm{GaN}$ base layers, which now match those of AlN/GaN heterostructures grown under standard conditions. In addition, we report on the properties of the 2DEG in structures where both the AlN and GaN were grown via FME at low temperature. Furthermore, DMHy was used as an alternative N-precursor for AlN and GaN growth, and subsequent films were characterized with atomic force microscopy (AFM), X-ray diffraction (XRD), Hall effect measurements, and transmission electron microscopy (TEM) to determine effects on crystallinity and microstructure. The LT MOCVD grown AlN/GaN heterostructures were analyzed to determine the viability of utilizing these methods on temperature sensitive substrates in the future.

\section{Experimental}

Samples in this study were grown with atmospheric pressure MOCVD. For LT layers, nitrogen was used as the carry gas, triethylgallium (TEGa) was used as the Ga-precursor, and trimethylaluminum (TMAl) was used as the Al-precursor; $\mathrm{NH}_{3}$ and DMHy were used as $\mathrm{N}$-precursors, with $\mathrm{NH}_{3}$ being used when not otherwise specified. Growth temperatures reported in this study were measured via a thermocouple located underneath the susceptor, such that the expected wafer surface temperature was $\sim 50{ }^{\circ} \mathrm{C}$ colder. Growth rate calibrations were conducted to determine precursor efficacy at various temperatures 
(300 to $550{ }^{\circ} \mathrm{C}$ ) and $\mathrm{N}$-precursor flows (2.1 to $3.9 \mathrm{mmol} / \mathrm{min} \mathrm{DMHy} ; 45$ to $268 \mathrm{mmol} / \mathrm{min}$ $\left.\mathrm{NH}_{3}\right)$ in which thin layers of AlN $(9.4 \mu \mathrm{mol} / \mathrm{min}$ TMAl) or GaN $(10.5 \mu \mathrm{mol} / \mathrm{min} \mathrm{TEGa})$ were grown directly on Si substrates using a continuous growth mode. These samples were then measured via ellipsometry (Woolam Spectroscopic Ellipsometer, M-2000DI) to determine layer thicknesses and growth rates were subsequently calculated.

Prior to the deposition of other LT layers, semi-insulating (0001) GaN base layers were grown in situ at standard high temperature with trimethylgallium (TMGa) and $\mathrm{NH}_{3}$ on sapphire substrates. FME was utilized for the LT $\left(550{ }^{\circ} \mathrm{C}\right)$ layers by continuously flowing the N-precursor and pulsing the metal-precursor. All LT growths utilized nitrogen as the carrier gas. Each FME cycle consisted of the metal-precursor flow being off for $9 \mathrm{~s}$, ramping up to a specified flow for $5 \mathrm{~s}$, holding at that flow rate for $5 \mathrm{~s}$, and then ramping down to zero flow for $5 \mathrm{~s}$. These parameters were previously optimized for LT GaN grown with $\mathrm{NH}_{3}$ in a separate study [20]. As further optimization would be necessary on different substrates in the future, we did not extensively alter the flow scheme here. GaN growth by FME was conducted with TEGa flows of $0.60 \mu \mathrm{mol} / \mathrm{min}$ and with either DMHy $(3.9 \mathrm{mmol} / \mathrm{min})$ or $\mathrm{NH}_{3}(143 \mathrm{mmol} / \mathrm{min})$. AlN growth by FME was conducted with either DMHy $(0.4 \mathrm{mmol} / \mathrm{min})$ or $\mathrm{NH}_{3}(143 \mathrm{mmol} / \mathrm{min})$ with TMAl flows of $0.075 \mu \mathrm{mol} / \mathrm{min}$ or $0.087 \mu \mathrm{mol} / \mathrm{min}$, respectively, to account for the difference in growth rate with different $\mathrm{N}$-precursors.

Sample G1 consisted of 300 cycles ( 4 nm) of LT FME GaN grown with DMHy on semi-insulating high temperature GaN. Corresponding LT GaN samples grown with $\mathrm{NH}_{3}$ were analyzed in detail in a prior work [20]. LT FME AlN films directly grown on high temperature GaN were grown with DMHy for 563 cycles $(\sim 15 \mathrm{~nm})$, sample A1, and $\mathrm{NH}_{3}$ for 375 cycles $(\sim 10 \mathrm{~nm})$, sample A2. An LT AlN/LT GaN sample was grown with both LT FME layers grown using $\mathrm{NH}_{3}$, with 375 cycles $(\sim 10 \mathrm{~nm})$ AlN on 600 cycles $(\sim 8 \mathrm{~nm}) \mathrm{GaN}$, sample A3. All LT layers were grown at $550{ }^{\circ} \mathrm{C}$ and are listed in Table 1.

Table 1. List of LT FME samples and continuously grown LT SIMS layers analyzed.

\begin{tabular}{ccccc}
\hline Sample & LT Layer(s) & N-Precursor(s) & Growth Mode & Analysis \\
\hline G1 & GaN & DMHy & FME & AFM \\
\hline A1 & AlN & DMHy & FME & AFM, XRD, Hall, TEM \\
\hline A2 & AlN & $\mathrm{NH}_{3}$ & FME & AFM, XRD, Hall, TEM \\
\hline $\mathrm{A} 3$ & $\mathrm{AlN} / \mathrm{GaN}$ & $\mathrm{NH}_{3}$ & FME & AFM, XRD, Hall, TEM \\
\hline $\mathrm{S} 1$ & $\mathrm{GaN}$ & $\mathrm{NH}_{3}$ & Continuous & SIMS \\
\hline $\mathrm{S} 2$ & $\mathrm{GaN}$ & $\mathrm{NH}_{3}+\mathrm{DMHy}$ & Continuous & SIMS \\
\hline $\mathrm{S} 3$ & $\mathrm{GaN}$ & $\mathrm{DMHy}$ & Continuous & SIMS \\
\hline
\end{tabular}

Samples were analyzed via AFM (Asylum MFP-3D) (Santa Barbara, CA, USA) to determine the morphology of samples with root mean square roughness calculated from $1 \mu \mathrm{m} \times 1 \mu \mathrm{m}$ micrographs. XRD (Panalytical MRD PRO) (Santa Barbara, CA, USA) $\omega-2 \theta$ scans about the (0004) GaN peak provided information about the relaxation and crystallinity of the AlN films when compared to simulated scans produced using Epitaxy software. Room temperature hall measurements on heterostructure AlN/GaN films used the van der Pauw technique on diced $1 \mathrm{~cm} \times 1 \mathrm{~cm}$ sample pieces to determine 2DEG characteristics. Cross-sectional TEM samples of AlN thin films were prepared using Thermo Fisher Scientific Helios 450 F1 DualBeam Focused Ion Beam. Final sample thinning was accomplished with $5 \mathrm{keV} \mathrm{Ga}^{+}$ions to remove beam damage. TEM imaging was performed with Thermo Fisher Scientific Osiris S/TEM operating at $200 \mathrm{kV}$, with energy dispersive X-ray spectroscopy (EDX) additionally performed.

Secondary ion mass spectrometry (SIMS, Cameca IMS 7 f Auto SIMS) (Santa Barbara, CA, USA) was conducted on a separate sample to determine the impurity content of GaN grown with different N-precursors. This SIMS sample consisted of a high temperature 
GaN-on-sapphire template with continuously grown LT $\left(550^{\circ} \mathrm{C}\right) \mathrm{GaN}$ layers separated by high temperature GaN. The growth rate calibration data were used to grow each layer with a constant growth rate of $0.082 \AA / \mathrm{s}$ for $25 \mathrm{~min}$, varying the TEGa flow rate as necessary. The $\mathrm{N}$-precursors for each layer were as follows: (S1) $135 \mathrm{mmol} / \mathrm{min} \mathrm{NH}_{3}$, (S2) $135 \mathrm{mmol} / \mathrm{min}$ $\mathrm{NH}_{3}$ and $3.9 \mathrm{mmol} / \mathrm{min}$ DMHy, (S3) $3.9 \mathrm{mmol} / \mathrm{min}$ DMHy.

\section{Results and Discussion}

Figure 1a shows the growth rate (GR) versus growth temperature data for GaN grown with either $\mathrm{NH}_{3}, \mathrm{DMHy}$, or a mixture of the two N-precursors, calibrated through continuous growth on silicon. $\mathrm{NH}_{3}$ and $\mathrm{DMHy}$ both showed significant growth in the 500 to $550{ }^{\circ} \mathrm{C}$ temperature range. At $500{ }^{\circ} \mathrm{C}$, growth was also conducted with a combination of N-precursors and the GR was close to that seen for the film grown with DMHy alone. At lower temperatures the GR with both precursors decreased, with the GR with DMHy dropping significantly below $500{ }^{\circ} \mathrm{C}$ whereas the GR with $\mathrm{NH}_{3}$ declined considerably below $450{ }^{\circ} \mathrm{C}$. The difference in the temperature at which the growth rate decreased may be associated with the presence of methyl groups during growth with DMHy. The methyl groups of the DMHy can exchange with the ethyl groups of the TEGa, leading to formation of Ga-methyl bonds, such that the benefits of a lower pyrolysis temperature of TEGa compared to TMGa may have been partially lost [29,30]. Further investigations are needed to clarify the mechanism. Very little growth was seen with DMHy below $400{ }^{\circ} \mathrm{C}$ and with $\mathrm{NH}_{3}$ below $350^{\circ} \mathrm{C}$. In Figure $1 \mathrm{~b}$, the GR is plotted versus the N-precursor flow for samples grown at $500{ }^{\circ} \mathrm{C}$ with varying $\mathrm{NH}_{3}$ or DMHy flows. The GR with DMHy was largely constant over the measured range, while the GR with $\mathrm{NH}_{3}$ decreased slightly at the highest explored $\mathrm{NH}_{3}$ flow of $250 \mathrm{mmol} / \mathrm{min}$. Despite the large difference in $\mathrm{N}$-precursor flow rates, the GRs being comparable suggested that the lower decomposition efficiency of $\mathrm{NH}_{3}$ compared to DMHy could be compensated by providing significantly higher $\mathrm{NH}_{3}$ than DMHy molar flows, and that the growth rate was largely determined by the TEGa flow in the range of the studied N-precursor flows.
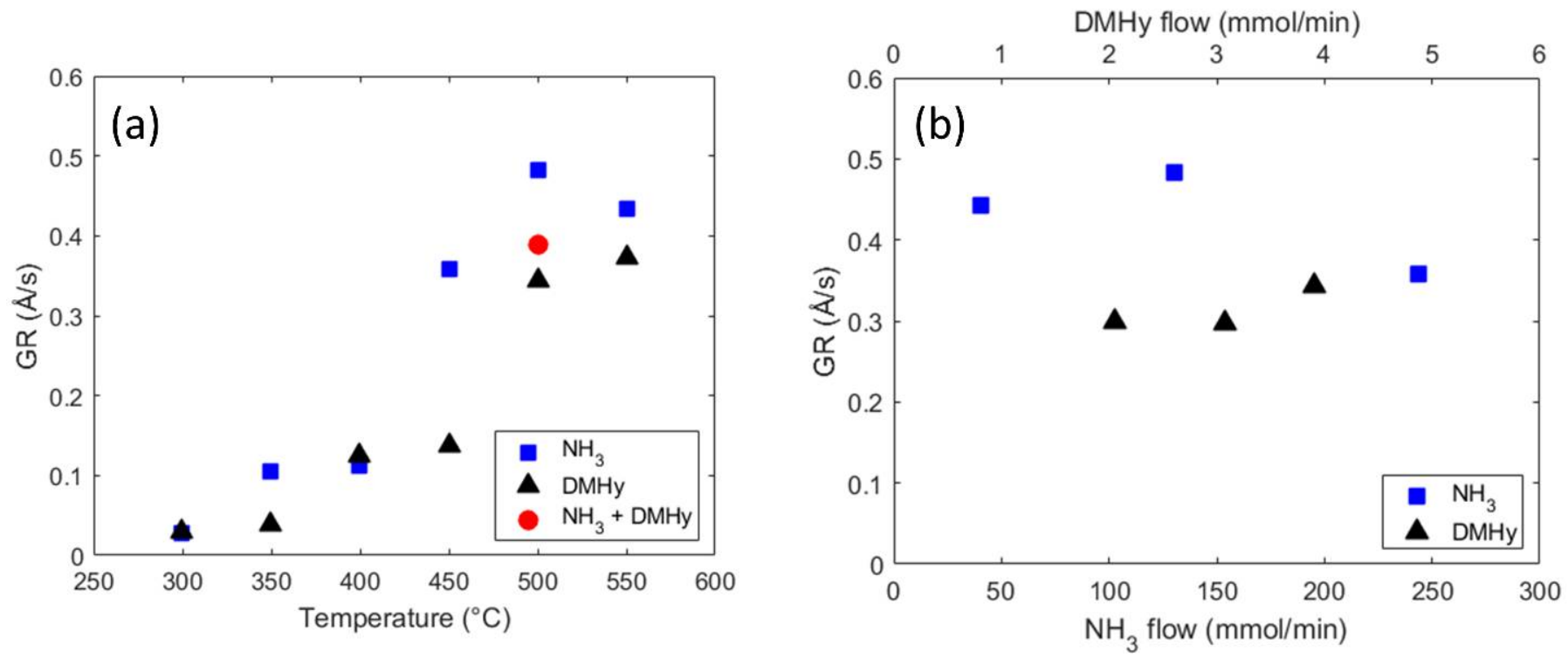

Figure 1. GR calibrations for GaN grown with TEGa $(10.5 \mu \mathrm{mol} / \mathrm{min})$ and either $\mathrm{NH}_{3}, \mathrm{DMHy}$, or both precursors. (a) GR versus temperature for $143 \mathrm{mmol} / \mathrm{min} \mathrm{NH} 3,3.9 \mathrm{mmol} / \mathrm{min} \mathrm{DMHy}$, and one data point for $143 \mathrm{mmol} / \mathrm{min} \mathrm{NH}_{3}+$ $3.9 \mathrm{mmol} / \mathrm{min} \mathrm{DMHy}$. (b) GR versus $\mathrm{N}$-precursor flow at $500{ }^{\circ} \mathrm{C}$ with the DMHy flow given on the top $x$-axis.

Selected samples from the GR calibration series were additionally grown directly on sapphire substrates. For growth with $\mathrm{NH}_{3}$, samples were colorless as expected, however GaN films grown with DMHy were dark in color (Figure 2). This effect was attributed to the formation of metal droplets due to the lower partial pressure of active nitrogen when 
growing with DMHy (lower V/III ratio) in combination with high levels of impurities in the films. To further investigate the latter, a sample was grown which consisted of LT GaN layers separated and capped by high temperature GaN. SIMS was conducted on this sample to determine the hydrogen, carbon, and oxygen impurity concentrations in the layers (Figure 3). All LT layers were grown continuously at $550{ }^{\circ} \mathrm{C}$ and were therefore expected to have higher impurity levels compared to layer grown in FME mode. To determine impurity concentrations, the SIMS peaks were integrated and divided by the expected layer thicknesses, assuming $12.3 \mathrm{~nm}$ for each (Table 2). It was seen that layer S1, grown with $\mathrm{NH}_{3}$, had the lowest carbon level of $3 \times 10^{19} \mathrm{~cm}^{-3}$ and S2, grown with a combination of N-precursors, exhibited a carbon concentration of $8 \times 10^{19} \mathrm{~cm}^{-3}$, over twice the carbon content of S1. The carbon level in layer S3, grown with only DMHy, amounted to $2 \times 10^{21} \mathrm{~cm}^{-3}$ and was nearly two orders of magnitude higher than that of layer S1. Oxygen levels in layers S1 and S2 were $7 \times 10^{17} \mathrm{~cm}^{-3}$ and $9 \times 10^{17} \mathrm{~cm}^{-3}$, respectively, significantly lower than the three times higher oxygen level in layer $\mathrm{S} 3$ of $3 \times 10^{18} \mathrm{~cm}^{-3}$.

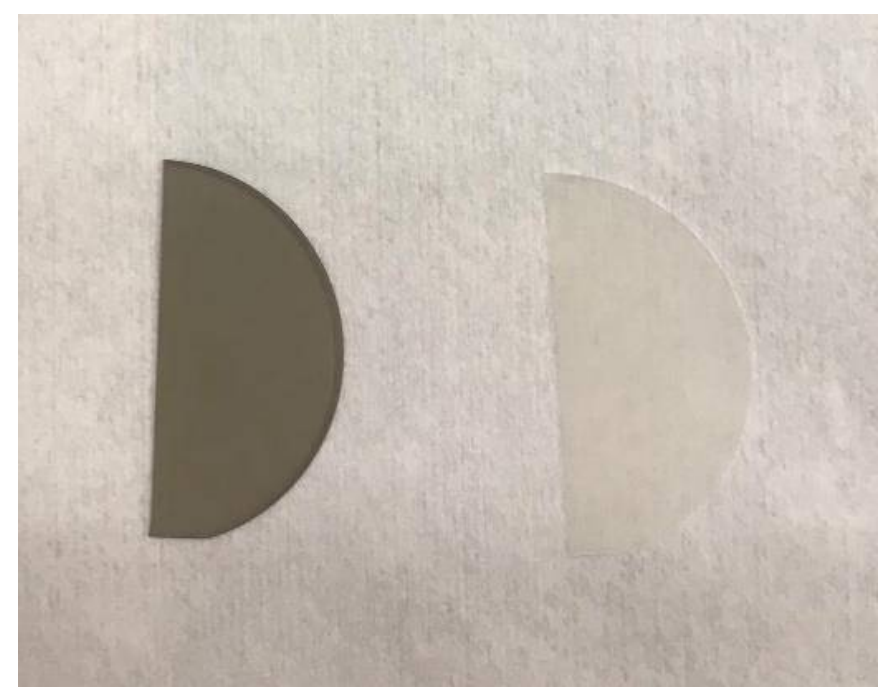

Figure 2. Photograph of LT GaN on sapphire samples. Left sample was $37 \mathrm{~nm}$ thick and grown with DMHy at $550{ }^{\circ} \mathrm{C}$ and right sample was $36 \mathrm{~nm}$ thick and grown with $\mathrm{NH}_{3}$ at $450{ }^{\circ} \mathrm{C}$.

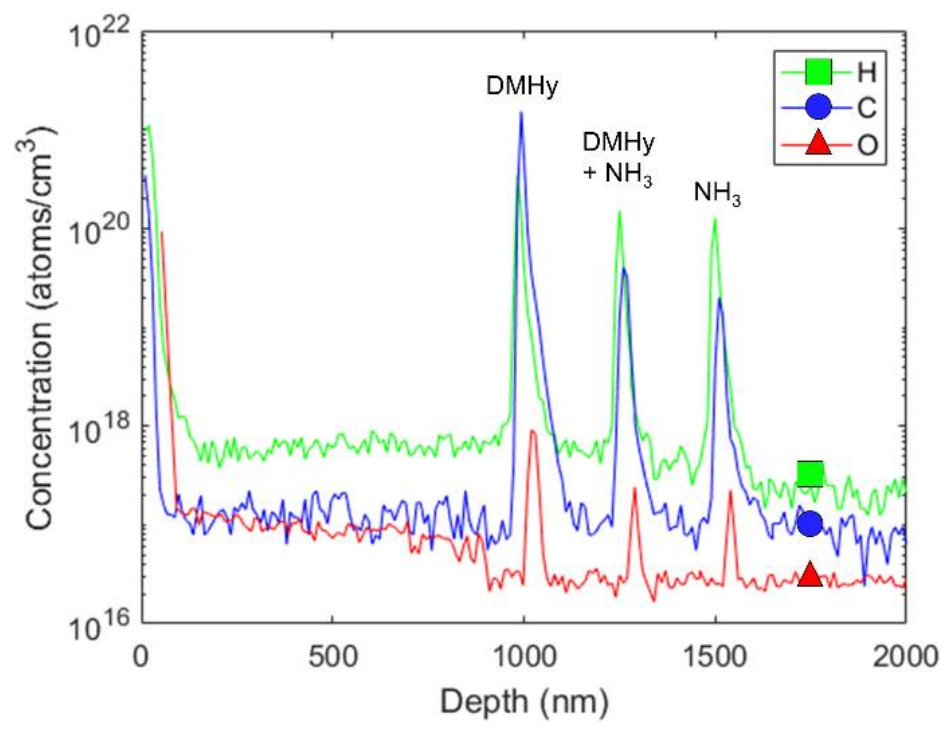

Figure 3. Hydrogen, carbon, and oxygen content in LT GaN layers determined by SIMS. The LT layers were grown continuously at $550{ }^{\circ} \mathrm{C}$ with varying N-precursors, from right to left: (S1) $135 \mathrm{mmol} / \mathrm{min}$ $\mathrm{NH}_{3}$, (S2) $135 \mathrm{mmol} / \mathrm{min} \mathrm{NH}_{3}$ and $3.9 \mathrm{mmol} / \mathrm{min} \mathrm{DMHy},(\mathrm{S} 3) 3.9 \mathrm{mmol} / \mathrm{min} \mathrm{DMHy}$. 
Table 2. Impurity concentrations (C, O) in LT GaN layers with varying N-precursors, determined from SIMS measurements.

\begin{tabular}{cccc}
\hline Layer & N-Precursor(s) & $\mathbf{C}$ & $\mathbf{O}$ \\
\hline $\mathrm{S} 1$ & $\mathrm{NH}_{3}$ & $3 \times 10^{19} \mathrm{~cm}^{-3}$ & $7 \times 10^{17} \mathrm{~cm}^{-3}$ \\
\hline $\mathrm{S} 2$ & $\mathrm{NH}_{3}+\mathrm{DMHy}$ & $8 \times 10^{19} \mathrm{~cm}^{-3}$ & $9 \times 10^{17} \mathrm{~cm}^{-3}$ \\
\hline $\mathrm{S} 3$ & $\mathrm{DMHy}$ & $2 \times 10^{21} \mathrm{~cm}^{-3}$ & $3 \times 10^{18} \mathrm{~cm}^{-3}$ \\
\hline
\end{tabular}

This indicated that carbon or oxygen may have been responsible for the dark color noted in previous samples grown with DMHy. The reduction of carbon going from S3 to S2 may be attributed to the better extraction of methyl groups from the DMHy with the presence of hydrogen provided by the $\mathrm{NH}_{3}$, although additional carbon was still introduced by the DMHy in the case of S2 as compared to S1. The methyl groups provided by the DMHy precursors allowed the formation of Ga-methyl bonds on the growth surface, resulting in an enhanced $C$ incorporation and impeding the advantages of using TEGa as precursor, which normally allows the growth of LT films with lower C impurity concentrations compared to TMGa, due to the easier cleavage of the Ga-ethyl compared to the Ga-methyl bond [29]. The relatively low oxygen level in S2 shows that the oxygen contamination could be suppressed by the addition of $\mathrm{NH}_{3}$, suggesting that the high O concentration in the GaN layer grown with DMHy alone (S3) was in part associated again with the significantly lower N-precursor partial pressure which was limited by the vapor pressure of DMHy.

When performed on high temperature GaN base layers, it was shown that LT FME $\mathrm{GaN}$ growth conducted at $550{ }^{\circ} \mathrm{C}$ with $\mathrm{NH}_{3}$ could result in a step-flow growth mode with low surface roughness [20]. When FME GaN was grown with DMHy on top of high temperature GaN (sample G1), AFM micrographs revealed rough films with features above $400 \mathrm{~nm}$ tall. These features may have been formed via metal-droplet assisted nanowire formation due to the low V/III ratios when growing with DMHy. Due to the successful growth of $\mathrm{GaN}$ with $\mathrm{NH}_{3}$ under similar conditions, $\mathrm{NH}_{3}$ was chosen as the $\mathrm{N}$-precursor of choice for LT GaN growth moving forward.

DMHy and $\mathrm{NH}_{3}$ were then compared as N-precursors for LT AlN growth. Despite concerns with DMHy for use in GaN growth, the growth of AlN with DMHy was expected to benefit from the lower N-precursor partial pressure due to the higher stability of AlN compared to GaN leading to lower V/III ratios being necessary for growth [31]. In addition, known pre-reactions between $\mathrm{NH}_{3}$ and TMAl make finding an alternative $\mathrm{N}$-precursor attractive. Figure 4 shows the GR versus temperature and GR versus N-precursor flow plots for AlN grown continuously on silicon. Unlike in the case of GaN growth, AlN growth with DMHy showed a higher GR than with $\mathrm{NH}_{3}$ at temperatures of $450{ }^{\circ} \mathrm{C}$ and higher (Figure 4a), most likely due to the pre-reactions between $\mathrm{NH}_{3}$ and TMAl limiting the AlN GR. The AlN films grown with both N-precursors present at $500{ }^{\circ} \mathrm{C}$ was seen to match the GR of $\mathrm{NH}_{3}$ alone, again most likely due to pre-reactions effectively reducing the available TMAl. At temperatures below $450{ }^{\circ} \mathrm{C}$ the GR with DMHy decreased and was seen to be lower than that with $\mathrm{NH}_{3}$. In comparison to previously studied growth with TEGa, the GR with DMHy remained high at somewhat lower temperatures due to the high pyrolysis of TMAl. Instead of being related to the group III precursor, the GR decrease with decreasing temperature was attributed to the decreased cracking efficiency of DMHy which was previously observed to occur in this temperature range [32]. While DMHy exhibited effectively no AlN growth at $300{ }^{\circ} \mathrm{C}$, the growth of $\mathrm{AlN}$ with $\mathrm{NH}_{3}$ was still appreciable down to these temperatures, although greatly reduced. This decrease in GR with the use of $\mathrm{NH}_{3}$ was likely a factor of the lower TMAl pyrolysis below $350^{\circ} \mathrm{C}$ [33]. For N-precursor variation studies conducted at $500^{\circ} \mathrm{C}$ (Figure 4b), the GR with DMHy was seen to be constant over the measured range, while the AlN GR with $\mathrm{NH}_{3}$ decreased slowly as more $\mathrm{NH}_{3}$ was available to cause pre-reactions with TMAl. As the targeted 
growth temperatures in this study were between $500{ }^{\circ} \mathrm{C}$ and $550{ }^{\circ} \mathrm{C}$, the growth at the lower temperatures was not further studied.
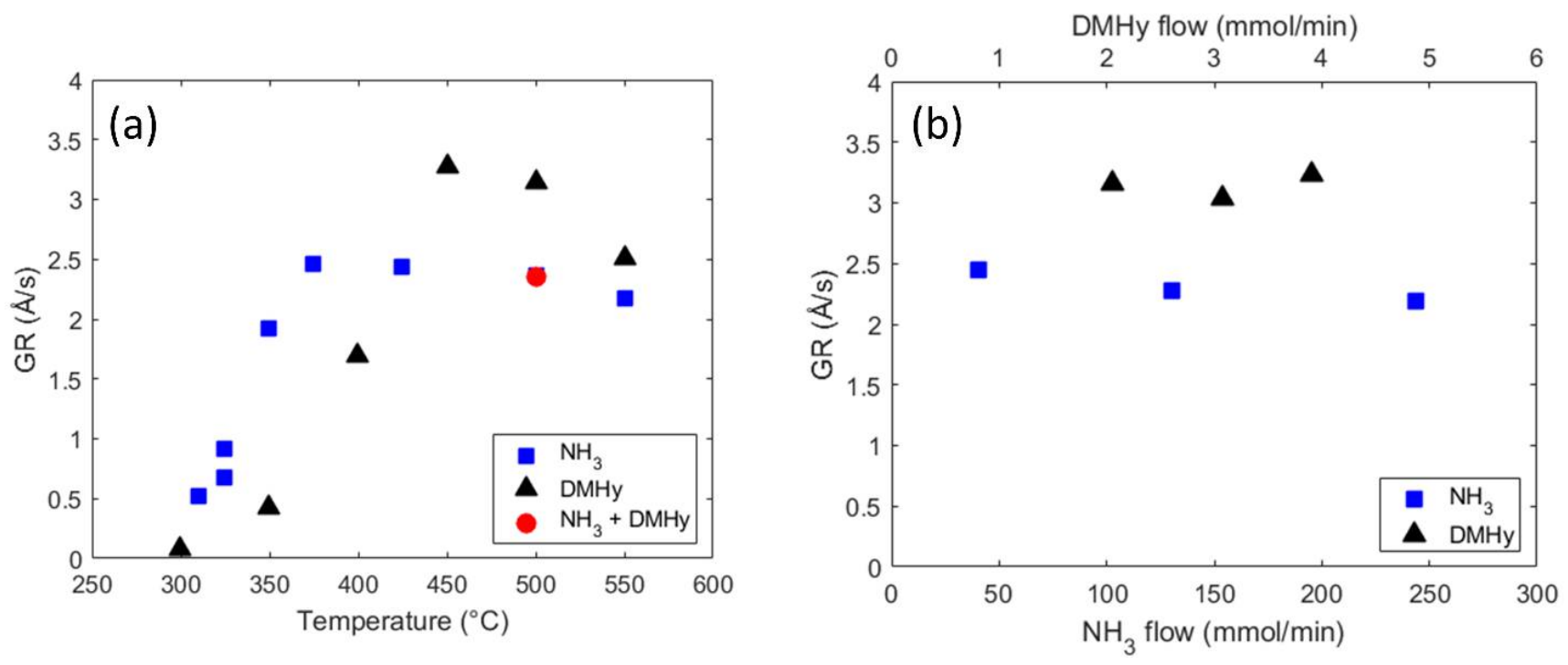

Figure 4. GR calibrations for AlN grown with $\mathrm{TMAl}(9.4 \mu \mathrm{mol} / \mathrm{min})$ and either $\mathrm{NH}_{3}$, DMHy, or both precursors. (a) GR versus temperature for $143 \mathrm{mmol} / \mathrm{min} \mathrm{NH}_{3}, 3.9 \mathrm{mmol} / \mathrm{min} \mathrm{DMHy}$, and one point for $143 \mathrm{mmol} / \mathrm{min} \mathrm{NH} 3+3.9 \mathrm{mmol} / \mathrm{min}$ DMHy. (b) GR versus N-precursor flow at $500{ }^{\circ} \mathrm{C}$ with the DMHy flow given off the top x-axis.

LT FME AlN was then grown on high temperature GaN using either DMHy (A1) or $\mathrm{NH}_{3}$ (A2). A third sample was grown which consisted of LT FME AlN on LT FME GaN on high temperature $\mathrm{GaN}$, all grown with $\mathrm{NH}_{3}$ (A3). Figure 5 shows AFM micrographs of these three samples. All samples exhibited a layer-by-layer growth mode unlike the step flow growth observed for FME GaN with $\mathrm{NH}_{3}$. While the LT FME AlN layer grown with $\mathrm{NH}_{3}$ (sample A2) had a very smooth surface with a root mean square roughness of $304 \mathrm{pm}$, sample A1 grown with DMHy was significantly rougher with a root mean square of $1.84 \mathrm{~nm}$. Sample A3, where the LT FME AlN layer had been grown on top of a thin LT GaN layer, exhibited a surface roughness of $770 \mathrm{pm}$. Optimization of the flow scheme via changing flow rates and times may serve to decrease these roughness values further, however that was outside of the scope of this work. The differences in morphology between A2 and A3 indicate that the LT GaN layer, despite its step-flow growth with good morphology, affected the growth mode of the LT AIN layer on top. The smaller step length on the surface of the LT GaN film as compared to the high temperature GaN film was likely responsible for the increased roughness of sample A3.

To gain information on the strain state and crystallinity of the LT AlN layers, XRD $\omega-2 \theta$ scans were conducted on the (004) GaN peak, Figure 6. Simulations of strained and relaxed layers of AlN on GaN were compared to the experimental scans. For sample A1, AlN grown with DMHy, little to no peak associated with AlN could be seen in the XRD scan. In contrast, sample $\mathrm{A} 2$ grown with $\mathrm{NH}_{3}$ showed a strong $\mathrm{AlN}$ related peak that was only slightly shifted from that expected for fully strained AlN. The small shift of the AlN peak towards the $\mathrm{GaN}$ peak could be due to some slight Ga incorporation, slight relaxation, or a combination of these effects. Note that the observed shift of the AlN peak in sample A2 was much less than in previous work, where a significantly larger shift of the AlN towards the GaN peak was observed, caused by Ga incorporation into the AlN films [18]. Fringe peaks were visible on either side of the A2 AlN peak corresponding to a thickness of $10 \mathrm{~nm}$. For sample A3, an asymmetric peak attributed to AlN was visible between that of the strained and relaxed AlN reflections. Similar to the A2 case, this may have been due to some Ga incorporation, relaxation, or both. 


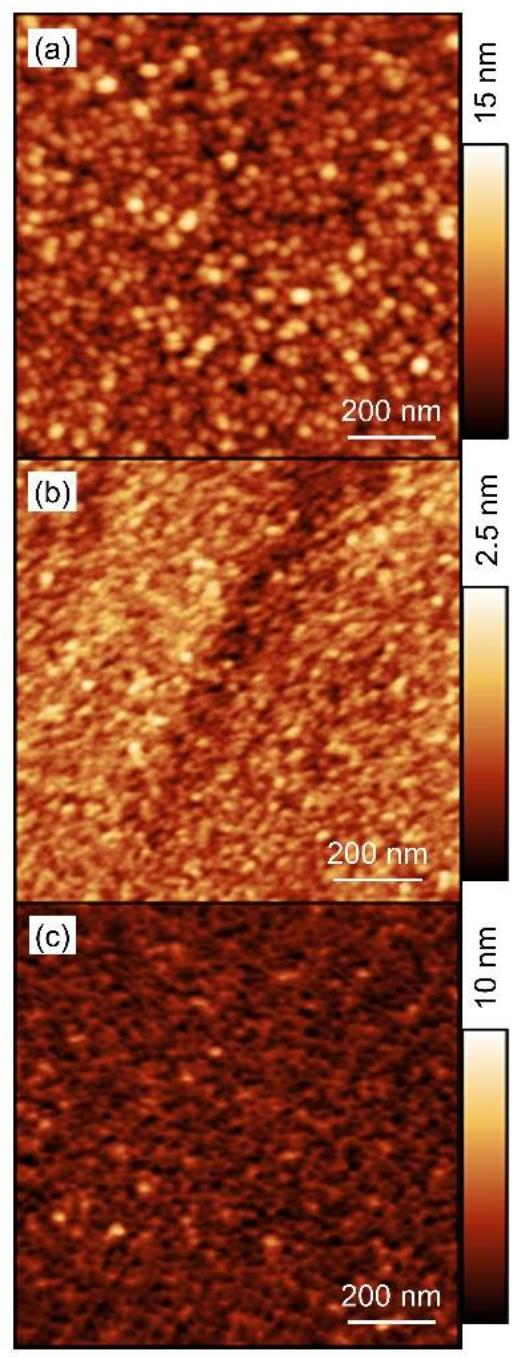

Figure 5. AFM micrographs of LT FME AIN samples: (a) A1, AlN grown with DMHy, (b) A2, AlN grown with $\mathrm{NH}_{3}$, and (c) $\mathrm{A} 3$, AlN grown on LT GaN with both layers grown with $\mathrm{NH}_{3}$. Scale bar at right goes from $0 \mathrm{~nm}$ to range given.

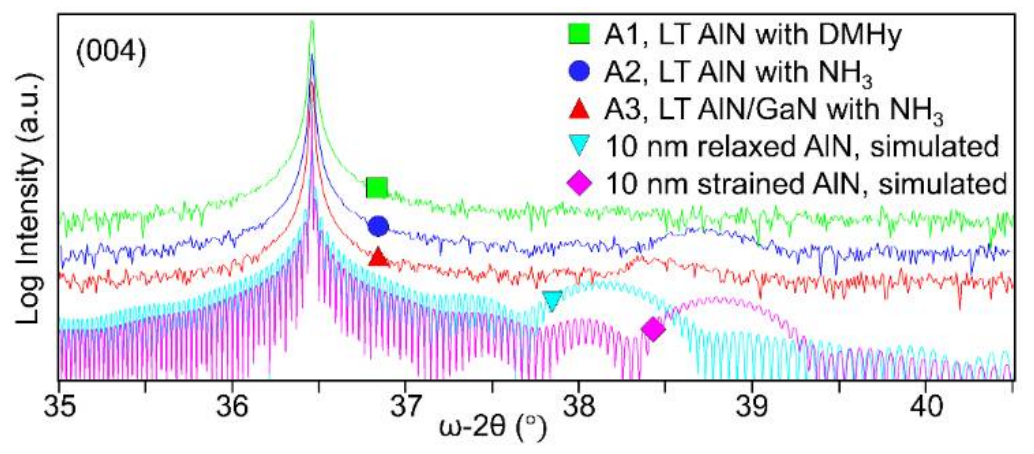

Figure 6. XRD $\omega-2 \theta$ scans of the (004) GaN peak for samples A1, A2, and A3. Simulated scans are also shown for $10 \mathrm{~nm}$ of either fully relaxed or fully strained AlN on GaN.

Hall measurements were conducted on samples A1, A2, and A3 to determine the characteristics of 2DEGs which were expected to form at their GaN/AlN interfaces. Sample A1 with AlN grown with DMHy was resistive and no 2DEG was measured. As the XRD data for this sample showed no measurable AlN peak and AFM showed a very rough film, most likely the AIN was polycrystalline in nature and therefore no 2DEG would form due to 
the lack of polarization. For samples A2 and A3, both grown with $\mathrm{NH}_{3}$, Hall measurements confirmed the presence of 2DEGs. For sample A2 composed of LT AlN on high temperature GaN an electron mobility $(\mu)$ of $540 \mathrm{~cm}^{2} / \mathrm{V} \cdot \mathrm{s}$ and a sheet charge $\left(\mathrm{n}_{\mathrm{s}}\right)$ of $3.76 \times 10^{13} \mathrm{~cm}^{-2}$ were measured, on par with results reported for $\mathrm{AlN} / \mathrm{GaN}$ heterostructures grown by MBE [11-13]. Despite the LT growth of the AIN layer, a high charge and mobility were obtained as the AlN was strained with high crystallinity. The properties of sample A2 were superior to those of the samples in our previous study, where unintentional Ga incorporation into the AIN layers was observed [20]. Sample A3, where a LT GaN layer was inserted underneath the LT AlN, exhibited an electron mobility of $230 \mathrm{~cm}^{2} / \mathrm{V} \cdot \mathrm{s}$ and a sheet charge of $1.59 \times 10^{13} \mathrm{~cm}^{-2}$ (Table 3). The causes leading to the different position and shape of the AlN XRD peak for this sample compared to sample A2, potential Ga incorporation and/or partial relaxation, are most likely also responsible for its reduced sheet charge. Compensating defects in the LT GaN layer, which was known to contain higher $\mathrm{C}$ and $\mathrm{O}$ impurity concentrations compared to high temperature $\mathrm{GaN}$, may have contributed as well [20]. The reduction in mobility was most likely caused by an increase in interface roughness associated with a smaller step length on the LT GaN as compared to the high temperature GaN surface prior to AlN growth [34]. The elevated impurity levels in the LT GaN layer in sample A3 may have also contributed.

Table 3. The 2DEG properties, electron mobility, sheet charge, and sheet resistance, of AlN/GaN heterostructures with LT AIN determined through room temperature Hall measurements.

\begin{tabular}{cccc}
\hline Sample & $\boldsymbol{\mu ( \mathbf { c m } ^ { 2 } / \mathbf { V } \cdot \mathbf { s } )}$ & $\mathbf{n}_{\mathbf{s}}\left(\mathbf{c m}^{-2}\right)$ & $\rho(\Omega / \square)$ \\
\hline A1 & resistive & resistive & resistive \\
\hline A2 & 540 & $3.76 \times 10^{13}$ & 310 \\
\hline A3 & 230 & $1.59 \times 10^{13}$ & 1690 \\
\hline
\end{tabular}

To further explain the difference between growth with DMHy versus $\mathrm{NH}_{3}$, LT AlN/GaN samples were studied with TEM. Figure 7 shows TEM cross-sections for sample Al, where the AlN layer was grown with DMHy. TEM results showed an AlN layer which was polycrystalline past the first few nanometers and had a rough surface consistent with that seen via AFM. The polycrystalline nature visible via TEM supported the lack of an AIN XRD peak and was consistent with the lack of 2DEG formation found via Hall measurements. From EDX measurements, it was seen that no significant Ga incorporation occurred in the LT AlN layer, with a compositionally sharp interface. Some Al enrichment was seen at the interface, in the area where the film showed reasonable crystallinity.

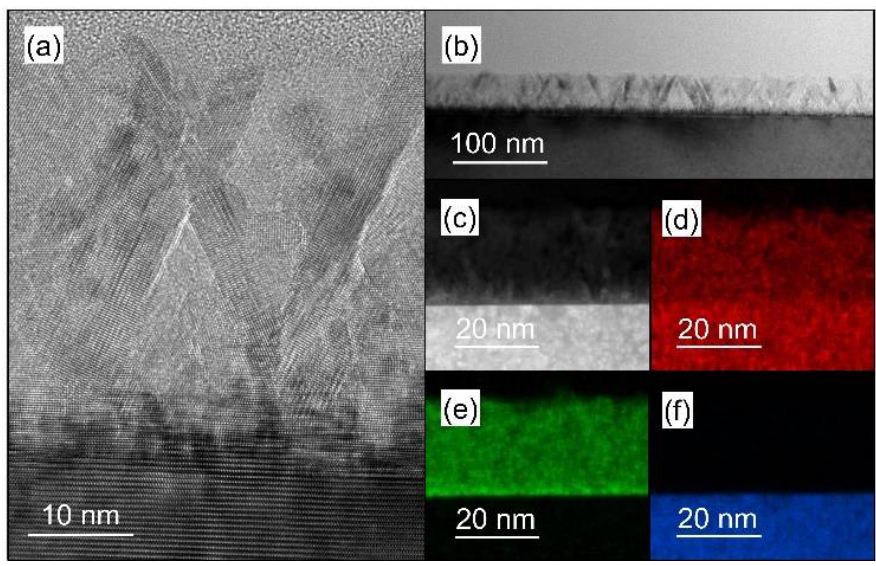

Figure 7. TEM cross-sections showing the LT AlN/high temperature GaN interface of samples A1, grown with DMHy. Two different magnifications are given in $(\mathbf{a}-\mathbf{c})$ showing a HAADF image. EDX images for $\mathrm{N}(\mathbf{d}), \mathrm{Al}(\mathbf{e})$, and $\mathrm{Ga}(\mathbf{f})$ are also shown. 
Sample A2, where the AlN layer was grown with $\mathrm{NH}_{3}$, exhibited higher AlN crystallinity and a lower surface roughness than A1 (Figure 8). This TEM result was consistent with XRD, Hall, and AFM measurements. From the XRD results it was already known that there was insignificant $\mathrm{Ga}$ incorporation. The absence of unintentional $\mathrm{Ga}$ incorporation in the AlN layers in this study was most likely due to a relatively clean growth chamber reducing the effects of $\mathrm{Ga}$ evaporations from $\mathrm{GaN}$ deposits in the chamber. The high crystallinity of the LT FME AlN layers grown with $\mathrm{NH}_{3}$ enabled the demonstration of LT FME AlN/high temperature GaN 2DEGs with properties similar to those grown under standard growth conditions by MBE.

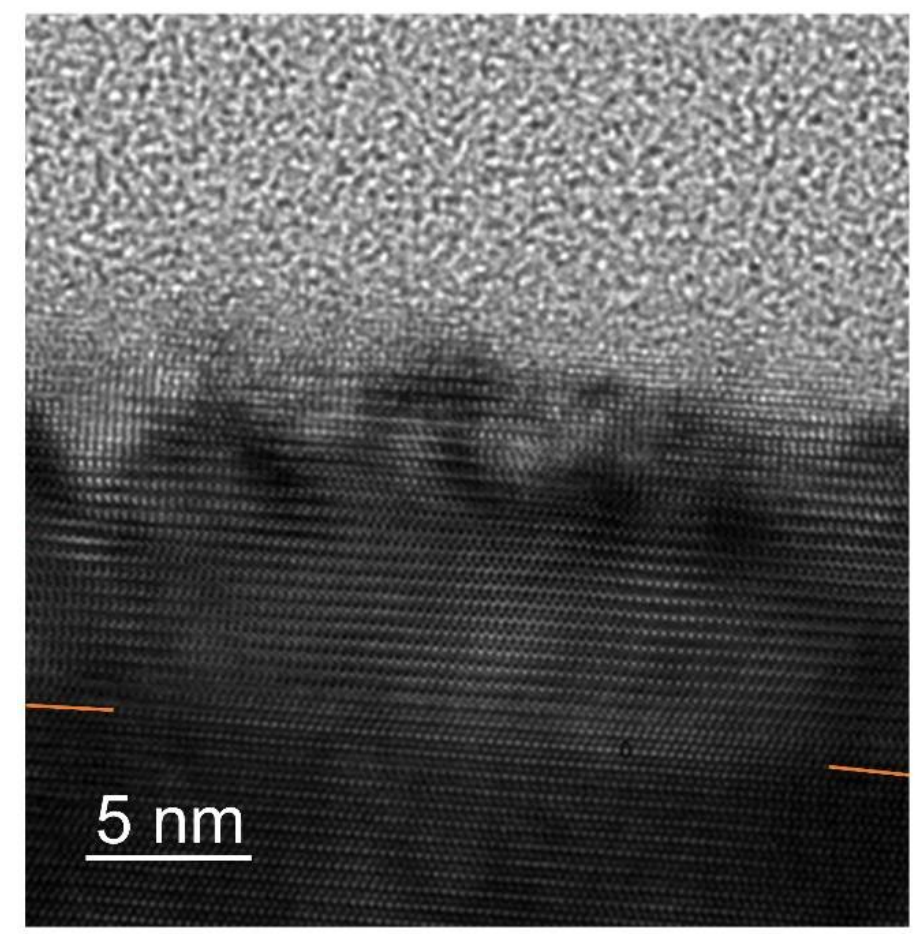

Figure 8. TEM cross-section showing the LT AlN/high temperature GaN interface of sample A2, grown with $\mathrm{NH}_{3}$. The orange lines indicate the interface between $\mathrm{AlN}$ and GaN.

\section{Conclusions}

MOCVD growth of GaN and AlN was conducted at $550{ }^{\circ} \mathrm{C}$ utilizing an FME scheme and either $\mathrm{NH}_{3}$ or DMHy as N-precursors. Initial studies of GR for both $\mathrm{N}$-precursors showed that DMHy did not provide a significant growth rate advantage for either GaN or AlN growth over the temperature range of 300 to $550{ }^{\circ} \mathrm{C}$. $\mathrm{NH}_{3}$ was found to produce higher quality films than DMHy for both GaN and AlN, with DMHy yielding incomplete films of $\mathrm{GaN}$ and polycrystalline films of AlN in the investigated parameter range. Additionally, DMHy was seen to increase the $\mathrm{C}$ and $\mathrm{O}$ impurity content in the films compared to $\mathrm{NH}_{3}$, further reason to continue to use $\mathrm{NH}_{3}$ given the currently available purity and cost of DMHy. Heterostructures consisting of LT AlN on high temperature GaN, grown with $\mathrm{NH}_{3}$, showed 2DEGs with high sheet charge and mobility of $3.76 \times 10^{13} \mathrm{~cm}^{-2}$ and $540 \mathrm{~cm}^{2} / \mathrm{V} \cdot \mathrm{s}$, respectively, comparable to AlN/GaN heterostructures demonstrated by molecular beam epitaxy. An LT GaN layer was introduced between the LT AlN and high temperature GaN and a 2DEG formed within the LT GaN. Although the 2DEG in the LT GaN had a charge and mobility about $50 \%$ less than the one in the high temperature $\mathrm{GaN}$, the values were still within a useful range for $\mathrm{GaN}$ electronics applications. These results make an important step towards expanding the device design space for integrating $\mathrm{GaN}$ with other material systems through highly scalable, LT MOCVD growth methods. 
Author Contributions: Conceptualization, C.E.R. and S.K.; methodology, C.E.R.; formal analysis, C.E.R., T.E.M., P.K. and S.K.; investigation, C.E.R., N.H., T.E.M. and A.A.O.; data curation, C.E.R. and S.K.; writing-original draft preparation, C.E.R.; writing-review and editing, C.E.R., S.N., S.P.D. and S.K.; supervision, S.N. and S.P.D.; project administration, P.K.; funding acquisition, S.N. and S.P.D. All authors have read and agreed to the published version of the manuscript.

Funding: This work was supported in part by the Solid State Lighting and Energy Electronics Center (SSLEEC) at the University of California, Santa Barbara and Intel Corporation (\#52522745). This work made use of MRL Central Facilities supported by the MRSEC Program of the National Science Foundation under awards No. DMR 1121053 and No. DMR 1720256.

Data Availability Statement: The data that support the findings of this study are available from the corresponding author upon reasonable request.

Conflicts of Interest: The authors have no conflict to disclose.

\section{References}

1. Flack, T.J.; Pushpakaran, B.N.; Bayne, S.B. GaN Technology for Power Electronic Applications: A Review. Electron. Mater. 2016, 45, 2673. [CrossRef]

2. Mishra, U.K.; Parikh, P.; Wu, Y.F. AlGaN/GaN HEMTs-An overview of device operation and applications. Proc. IEEE 2002, 90, 1022. [CrossRef]

3. Shur, M.S. GaN based transistors for high power applications. Solid. State. Electron. 1998, 42, 2131. [CrossRef]

4. Tanabe, K.; Rae, T.; Watanabe, K.; Arakawa, Y. High-temperature $1.3 \mu \mathrm{m}$ InAs/GaAs quantum dot lasers on Si substrates fabricated by wafer bonding. Appl. Phys. Express 2013, 6, 082703. [CrossRef]

5. Chen, S.; Li, W.; Wu, J.; Jiang, Q.; Tang, M.; Shutts, S.; Elliott, S.N.; Sobiesierski, A.; Seeds, A.J.; Ross, I.; et al. Electrically pumped continuous-wave III-V quantum dot lasers on silicon. Nat. Photonics 2016, 10, 307. [CrossRef]

6. Then, H.W.; Radosavljevic, M.; Desai, N.; Ehlert, R.; Hadagali, V.; Jun, K.; Koirala, P.; Minutillo, N.; Kotlyar, R.; Oni, A.; et al. Advances in Research on 300mm gallium nitride-on-Si(111) NMOS transistor and silicon CMOS integration. Tech. Dig. Int. Electron Devices Meet. IEDM 2020, 27, 3.

7. Then, H.W.; Radosavljevic, M.; Jun, K.; Koirala, P.; Krist, B.; Talukdar, T.; Thomas, N.; Fischer, P. Gallium Nitride and Silicon Transistors on $300 \mathrm{~mm}$ Silicon Wafers Enabled by 3-D Monolithic Heterogeneous Integration. IEEE Trans. Electron. Devices 2020, 67, 5306. [CrossRef]

8. Chen, K.J.; Haberlen, O.; Lidow, A.; Tsai, C.L.; Ueda, T.; Uemoto, Y.; Wu, Y. GaN-on-Si power technology: Devices and applications. IEEE Trans. Electron Devices 2017, 64, 779. [CrossRef]

9. Davenport, M.L.; Skendži, S.; Volet, N.; Hulme, J.C.; Heck, M.J.R.; Bowers, J.E. Heterogeneous Silicon/III-V Semiconductor Optical Amplifiers. IEEE J. Sel. Top. Quantum Electron. 2016, 22, 3100111. [CrossRef]

10. Heck, M.J.R.; Chen, H.-W.; Fang, A.W.; Koch, B.R.; Liang, D.; Park, H.; Sysak, M.N.; Bowers, J.E. Hybrid Silicon Photonics for Optical Interconnects. IEEE J. Sel. Top. Quantum Electron. 2011, 17, 333. [CrossRef]

11. Smorchkova, I.P.; Chen, L.; Mates, T.; Shen, L.; Heikman, S.; Moran, B.; Keller, S.; DenBaars, S.P.; Speck, J.S.; Mishra, U.K. $\mathrm{AlN} / \mathrm{GaN}$ and $(\mathrm{Al}, \mathrm{Ga}) \mathrm{N} / \mathrm{AlN} / \mathrm{GaN}$ two-dimensional electron gas structures grown by plasma-assisted molecular-beam epitaxy. J. Appl. Phys. 2001, 90, 5196. [CrossRef]

12. Faria, F.A.; Nomoto, K.; Hu, Z.; Rouvimov, S.; Xing, H.; Jena, D.J. Low temperature AlN growth by MBE and its application in HEMTs. Cryst. Growth 2015, 425, 133. [CrossRef]

13. Kaun, S.W.; Mazumder, B.; Fireman, M.N.; Kyle, E.C.H.; Mishra, U.K.; Speck, J.S. Pure AlN layers in metal-polar Al$\mathrm{GaN} / \mathrm{AlN} / \mathrm{GaN}$ and AlN/GaN heterostructures grown by low-temperature ammonia-based molecular beam epitaxy. Semicond. Sci. Technol. 2015, 30, 055010. [CrossRef]

14. Kobayashi, N.; Makimoto, T.; Horikoshi, Y. Flow-Rate Modulation Epitaxy of GaAs. Jpn. J. Appl. Phys. 1985, 24, L962. [CrossRef]

15. Khan, M.A.; Skogman, R.A.; van Hove, J.M.; Olson, D.T.; Kuznia, J.N. Atomic layer epitaxy of GaN over sapphire using switched metalorganic chemical vapor deposition. Appl. Phys. Lett. 1992, 60, 1366. [CrossRef]

16. Suntola, T. Atomic layer epitaxy. Thin Solid Films 1992, 216, 84. [CrossRef]

17. Khan, M.A.; Kuznia, J.N.; Skogman, R.A.; Olson, D.T.; Millan, M.M.; Choyke, W.J. Low pressure metalorganic chemical vapor deposition of AlN over sapphire substrates. Appl. Phys. Lett. 1992, 61, 2539. [CrossRef]

18. Reilly, C.E.; Hatui, N.; Mates, T.E.; Nakamura, S.; Denbaars, S.P.; Keller, S. 2DEGs formed in AlN/GaN HEMT structures with AlN grown at low temperature. Appl. Phys. Lett. 2021, 118, 222103. [CrossRef]

19. Fareed, Q.; Gaska, R.; Shur, M.S. Migration enhanced metal organic chemical vapor deposition of AlN/GaN/InN-based heterostructures. Int. Semicond. Device Res. Symp. 2003, 2003, 402.

20. Reilly, C.E.; Mates, T.E.; Webb, M.; Nakamura, S.; DenBaars, S.P.; Keller, S. Flow modulation metalorganic vapor phase epitaxy of $\mathrm{GaN}$ at temperatures below $600{ }^{\circ} \mathrm{C}$. Semicond. Sci. Technol. 2020, 35, 095014. [CrossRef]

21. Kobayashi, N.; Horikoshi, Y. Improved flatness in GaAs/AlGaAs heterointerfaces grown by flow-rate modulation epitaxy. Appl. Phys. Lett. 1987, 50, 909. [CrossRef] 
22. Horikoshi, Y. Advanced epitaxial growth techniques: Atomic layer epitaxy and migration-enhanced epitaxy. J. Cryst. Growth 1999, 201-202, 150. [CrossRef]

23. Keller, S.; Ben-Yaacov, I.; Denbaars, P.; Mishra, U.K. Flow modulation epitaxy of InN/GaN heterostructures; towards InN based HEMTs. Nitride Semicond. 2000, 1, 233.

24. Bourret-Courchesne, E.D.; Ye, Q.; Yu, K.M.; Ager, J.W. Evolution of crystallinity of GaN layers grown at low temperature on sapphire with dimethylhydrazine and triethylgallium. J. Cryst. Growth 2001, 231, 89. [CrossRef]

25. Gautier, S.; Sartel, C.; Ould-Saad, S.; Martin, J.; Sirenko, A.; Ougazzaden, A. GaN materials growth by MOVPE in a new-design reactor using DMHy and $\mathrm{NH}_{3}$. J. Cryst. Growth 2007, 298, 428. [CrossRef]

26. Sartel, C.; Gautier, S.; Hamady, S.O.S.; Maloufi, N.; Martin, J.; Sirenko, A.; Ougazzaden, A. Low temperature homoepitaxy of GaN by LP-MOVPE using Dimethylhydrazine and nitrogen. Superlattices Microstruct. 2006, 40, 476. [CrossRef]

27. Hsu, Y.J.; Hong, L.S.; Tsay, J.E. Metalorganic vapor-phase epitaxy of GaN from trimethylgallium and tertiarybutylhydrazine. J. Cryst. Growth 2003, 252, 144. [CrossRef]

28. Ruffenach, S.; Moret, M.; Briot, O.; Gil, B.; Giesen, C.; Heuken, M.; Rushworth, S.; Leese, T.; Succi, M. Alternative precursors for MOVPE growth of InN and GaN at low temperature. J. Cryst. Growth 2009, 311, 2791. [CrossRef]

29. Stringfellow, G.B. Organometallic Vapor-Phase Epitaxy: Theory and Practice, 2nd ed.; Academic Press: Cambridge, MA, USA, 1999.

30. Bourret-Courchesne, E.; Ye, Q.; Peters, D.W.; Arnold, J.; Ahmed, M.; Irvine, S.J.C.; Kanjolia, R.; Smith, L.M.; Rushworth, S.A. Pyrolysis of dimethylhydrazine and its co-pyrolysis with triethylgallium. J. Cryst. Growth 2000, 217, 47-54. [CrossRef]

31. MacChesney, J.B.; Bridenbaugh, P.M.; O'Connor, P.B. Thermal stability of indium nitride at elevated temperatures and nitrogen pressures. Mater. Res. Bull. 1970, 5, 783. [CrossRef]

32. Lee, R.T.; Stringfellow, G.B. Pyrolysis of 1,1 dimethylhydrazine for OMVPE growth. J. Electron. Mater. 1999, $28,963-969$. [CrossRef]

33. Squire, D.W.; Dulcey, C.S.; Lin, M.C. Mechanistic studies of the decomposition of trimethylaluminum on heated surfaces. J. Vac. Sci. Technol. B 1985, 3, 1513-1519. [CrossRef]

34. Keller, S.; Parish, G.; Fini, P.T.; Heikman, S.; Chen, C.H.; Zhang, N.; DenBaars, S.P.; Mishra, U.K.; Wu, Y.F. Metalorganic chemical vapor deposition of high mobility AlGaN/GaN heterostructures. J. Appl. Phys. 1999, 86, 5850. [CrossRef] 